\title{
Design como Fator Colaborativo: práticas e inovação em cerâmica artesanal.
}

Design as a Collaborative Factor: practices and innovation in handmade ceramics.

MIRANDA, Samuel da Silva; Mestrando, Universidade Federal do Maranhão

samueldsm@yahoo.com

CARACAS, Luciana Bugarin; Ms; Universidade Federal do Maranhão

l.caracas@uol.com.br

SANTOS, Denilson Moreira; Dr; Universidade Federal do Maranhão

denilson.santos@ufma.br

\section{Resumo}

Este trabalho apresenta resultados de experiências científicas, promovidas pelo Laboratório de Design Cerâmico-LDC da Universidade Federal do Maranhão-UFMA, acerca da aplicação de um material que busca o fator de inovação no fazer artesanal cerâmico. O chamado pó de osso (PO) bovino é atrelado à massa cerâmica formando assim um compósito que adere as peças produzidas, através de técnicas artesanais, fatores de inovação, evidenciado principalmente pelo resultado gerado em design de superfície, por meio de técnicas de acabamento/vitrificação. A pesquisa envolveu a participação de grupos artesanais, a Associação de Artesãos de São José de Ribamar AASJR, na região metropolitana, e a Olaria localizada no município de Rosário, interior do Maranhão. Sendo assim, a proposta versou pela apresentação dos resultados da pesquisa para os grupamentos e fomentou o desenvolvimento das práticas por eles exercidas, sem agredir o fazer artesanal, genuíno das comunidades.

Palavras Chave: Design, Cerâmica, Pó de Osso.

\begin{abstract}
This work presents results of scientific experiments, promoted by the Laboratory of Ceramic DesignLDC of the Federal University of Maranhão-UFMA, about the application of a material that seeks the innovation factor in the ceramic handicraft making. The so-called bovine bone powder (PO) is attached to the ceramic mass, thus forming a composite that adheres to the parts produced through craft techniques, innovation factors, evidenced mainly by the result generated in surface design by means of finishing / vitrification. The research involved the participation of artisan groups, the Artisans Association of São José de Ribamar - AASJR, in the metropolitan region, and the Pottery located in the municipality of Rosario, in the interior of Maranhão. Thus, the proposal was based on the presentation of the results of the research for the groupings and encouraged the development of the practices they practice, without harming the genuine artisanal making of the communities.
\end{abstract}

Keywords: Design, Ceramics, Bone Dust. 


\section{Introdução}

Diante da realidade em que vivenciamos, considera-se relevante buscar possibilidades de inovação para a produção artesanal, pois no Brasil muitos cidadãos possuem seus rendimentos a partir da produção artesanal, explorando as mais diversas técnicas: cestaria, tecelagem, bijuterias, costura, cerâmica, rendas, etc.

Nestes termos, ampliam-se os estudos acerca da relação entre design, artesanato, inovação, buscando conhecer aspectos positivos, relativos a essa interação, na vida das pessoas, na vida dos artesãos. Sendo assim, estudiosos do design, como Thackara (2008) e Manzini (2008) e Manzini; Vezzoli (2005), entre outros, ressaltam o respeito ao homem que, como sujeito social, deve também ser levado em consideração, deve participar dos processos, das decisões, das escolhas, favorecendo a inclusão socioeconômica, o bem-estar e o desenvolvimento sustentável. Pensar em um produto artesanal, não é apenas torná-lo contemplativo ou explorar sua funcionalidade, é, sim, pensar nas mãos que o constroem.

Pensar sobre produção artesanal despertou o interesse sobre os que trabalham com a elaboração de peças em cerâmica. Especialmente no estado do Maranhão algumas localidades têm grupos que se dedicam a este setor, como os municípios de Rosário, Itamatatiua, São José de Ribamar, Mirinzal e outros. Em sua maioria, esses grupamentos apresentam dificuldades diversas e inovações podem promover melhorias nessa realidade. O design, apoiando o sujeito social, muito pode fazer por grupamentos artesanais. Para isso, um dos fatores essenciais é trabalhar colaborativamente, compreendendo o local e o grupo com que se pretende interagir.

Com isso, os grupos de produção contemporânea, associados ao desenvolvimento deste trabalho são dos municípios maranhenses de Rosário e São Jose de Ribamar. De início, especialmente na Associação de Artesãos de São José de Ribamar (AASJR), a equipe de pesquisadores do Laboratório de Design Cerâmico (LDC), vinculado ao Departamento de Desenho e Tecnologia - DEDET e ao Mestrado em Design, do Centro de Ciências Exatas e Tecnologia (CCET) da Universidade Federal do Maranhão - UFMA investiu em um período de aproximação e reconhecimento do grupo. Neste período foram realizadas interações, visitas, entrevistas, jogos etc. Procurava-se apreender tanto como eram os processos e produtos, quanto o que pensam e sentem as artesãs acerca do trabalho, da produção, quais suas perspectivas e interesses. Estratégias e escolhas foram definidas em conjunto pelos pesquisadores designers e artesãs. Entre estas, uma se referia à vontade de inovação técnica e estética, mas observamos também, as dificuldades quanto à perda de peças produzidas que podem ser melhoradas com o conhecimento científico e tecnológico.

Era momento de pensar na apresentação e nas primeiras experiências de aplicação da pesquisa de materiais sobre um compósito - argila com pó de osso bovino - desenvolvido no LDC, evidenciando o fator de inovação. O compósito apresentou melhorias técnicas e estéticas, além de ambientais. Sob a supervisão da Professora Me. Luciana Caracas e o mestrando Samuel Miranda, também do LDC, experimentações artesanais foram realizadas, com produtos e testes, verificando acabamentos de superfície naturais e vitrificados, entre outros.

A cerâmica na região do Maranhão utiliza, tradicionalmente, argila e água. A inserção do pó de osso (PO) bovino na massa cerâmica e no processo, atrelado aos métodos de design, caracterizase como fator de inovação, pois a proposta minimiza as perdas no processo, além de reduzir o uso dos recursos naturais não renováveis (a argila) e utilizar matéria-prima renovável (pó de osso), 
valorizando o trabalho das pessoas envolvidas, visto focar no fazer manual, além de favorecer a ampliação do mercado de produtos cerâmicos, apresentando design de superfície diferenciado, deste modo, contribuindo para a geração de emprego e renda. A inserção do pó de osso na cerâmica traz aspectos importantes à valorização do trabalho realizado nos grupos artesanais na região. Portanto, isso é pensar na produção artesanal, com um olhar de respeito aos recursos ambientais e às pessoas envolvidas no processo, como essenciais para o estabelecimento de uma real qualidade de vida e trabalho.

Assim, o objetivo geral da pesquisa é apresentar os aspectos relativos às experimentações realizadas pela equipe do Laboratório de Design Cerâmico, particularmente os produtos desenvolvidos com o uso do compósito (argila com adição do pó de osso bovino), visando contribuir para a produção artesanal local, bem como, favorecer inovações e reflexões sobre o tema. Apresentar também aos grupos artesanais considerados, essas abordagens e demonstrar possibilidades de inovação através de novos materiais e os resultados que podem ser gerados.

Enfim, tendo uma olaria na cidade de Rosário e uma associação de artesãos em São José de Ribamar como piloto, o presente trabalho visa contribuir para o desenvolvimento da produção local e a inclusão socioeconômica, a priori nas comunidades citadas, porém, permitindo a expansão futura desse conhecimento para outros grupos artesanais.

\section{Percurso Metodológico}

Diversas experiências foram sendo realizadas no decorrer do trabalho desenvolvido, com o intento de promover aplicações práticas e artesanais, utilizando o compósito em produtos de design, tais como vasos, luminárias, placas decorativas de parede, dentre outros.

Para tal, realizamos pesquisa bibliográfica e apoiamo-nos, especialmente, tanto nos estudos de materiais desenvolvidos pelo Professor Dr. Denilson Santos coordenador do LDC e alunos bolsistas, através de órgãos de fomento à pesquisa como o Programa Institucional de Bolsas de Iniciação Científica-Pibic (CNPQ), quanto às experiências científicas e empíricas adquiridas no Laboratório através dos projetos de pesquisa e extensão, concretizadas pelo apoio de pesquisas relacionadas ao Programa Institucional de Bolsas de Iniciação Tecnológica-Pibit (UFMA), vinculado ao Departamento de Empreendedorismo e Inovação - Demi e a Fundação de Amparo à Pesquisa e ao Desenvolvimento Científico e Tecnológico do Maranhão - FAPEMA.

Esta fase forneceu subsídios para o entendimento do objeto de estudo e embasamento da pesquisa. O trabalho envolveu busca de referencial teórico sobre os temas abordados, levantamentos e sistematização de informações, através de estudos de artigos, dissertações, livros etc.

Nas etapas diversas, utilizamos a observação assistemática e sistemática e o registro das etapas, com registro fotográfico e uso de caderno de campo e tabela paramétrica, visando o controle dos resultados. Na execução dos produtos em argila com adição de PO, foram utilizadas técnicas de produção artesanal e modelagens diversas tendo em vista requisitos técnico-produtivos relativos aos meios e aos métodos de fabricação disponíveis, em especial equipamentos, mão de obra local, dificuldades e facilidades na execução, qualidade final etc.

Para o desenvolvimento dos produtos/artefatos, adaptamos as metodologias de design, tradicionais e do design participativo, incluindo a determinação do tema/produto com a identificação do problema e seus elementos; a coleta e análise de dados; a etapa da criatividade 
com a geração e análise de ideias; desenvolvimento das ideias; a experimentação dos materiais e técnicas; execução de modelos, testes, protótipos; avaliação e reajuste das propostas, enfim, chegar às chamadas soluções que foram adaptadas e depois compartilhadas com os grupos envolvidos.

Com os artefatos cerâmicos foram feitos testes de vitrificação, a fim de verificar possibilidades do design de superfície. Nesse processo, outras técnicas e oficinais de produção aconteciam na olaria em Rosário e na Associação de Artesãos de São José de Ribamar - AASJR como experimento piloto, para uso do compósito pelos artesãos. Os resultados deste trabalho foram analisados, durante todo o percurso, com base em teorias do design de forma a promover uma reflexão sobre as possibilidades de futuro, tendo em vista aspectos técnico-científicos e práticos.

\section{Produção Artesanal, Design e Inovação}

É pertinente destacar que a produção artesanal é uma atividade humana histórica que preserva aspectos culturais de vários povos e comunidades. No entanto, o conhecimento vivido por esses grupos deve ser preservado com a intenção de cultivar a permanecia das experiências apreendidas com o passar dos anos. Tendo em vista esse aspecto, profissionais como o designer devem desempenhar com atenção suas contribuições, de forma a respeitar os saberes dos grupos artesanais, sendo eles tradicionais ou não.

Segundo Krucken (2009), a contribuição do design para a valorização de produtos locais pode ser agrupada de três formas: o designer deve promover a qualidade dos produtos, dos territórios e dos processos de fabricação; deve apoiar a comunicação e aproximar produtores e consumidores, intensificando as relações territoriais; além de apoiar o desenvolvimento de arranjos produtivos e cadeias de valor sustentáveis, visando ao fortalecimento de micro e pequenas empresas.

O processo da produção artesanal apresenta uma clara importância no contexto em que ela é vivida e exercida, recebendo influências acerca do momento e da cultura. Martins (2013), afirma que na esteira dessa concepção, o produto artesanal contribui não só para a compreensão de ser/estar cultural, mas, sobretudo do ponto de vista de uma estética que capta as mudanças de seu tempo e as práticas vigentes.

Em busca da inovação o compósito pó de osso bovino associado à cerâmica, contribui de forma significativa nesse processo. $\mathrm{O}$ aporte do design pode ser entendido nessa questão, pois a experiência do pó de osso coopera e adere elementos essências na diferenciação das peças em cerâmica. Para Krucken (2009), a busca por agregar valor a produtos, fortalecendo e estimulando a identidade local, é um forte impulsionador do investimento em design. O pó de osso bovino pode exercer um papel fundamental na composição das peças em cerâmica, pois acrescenta valores ambientais e estético-visuais ao design de superfície além de fornecer aspectos estruturais ao material.

\section{Grupos Artesanais}

Desenvolver trabalhos junto a comunidades e/ou grupos artesanais agrega valor ao estudo e concebe conhecimento mútuo para ambas as partes: pesquisador-pesquisado. No caso do trabalho desenvolvido e aqui apresentado, duas comunidades foram consideradas: a olaria de seu Amarildo (proprietário) em Rosário - MA e a AASJR coordenada pela artesã Sâmia Matos.

O processo de interação entre design e artesanato neste trabalho, efetivou-se através de parceria entre membros da UFMA (professores e discentes pesquisadores / laboratório) com a 
Associação de Artesãos de São José de Ribamar - AASJR e olaria em Rosário - MA (olaria do Senhor Amarildo, considerada como piloto), visando tanto à construção de conhecimentos (acerca de materiais e processos, de sustentabilidade, etc.) quanto à criação de artefatos, que ampliarão suas possibilidades no mercado.

Para isso foram necessárias visitas técnicas, oficinas e seminários, com o objetivo de apresentar as pesquisas desenvolvidas, bem como a troca de experiências e transpor tecnologia referente à execução de produtos com o compósito, além da troca de informações a respeito do trato da argila e do pó de osso (PO), modelagem, acabamento e queima, entre outros.

\title{
4.1 Associação de Artesãos de São José de Ribamar
}

A AASJR foi uma das comunidades envolvidas neste estudo. Sediada no município de São José de Ribamar que fica localizado a $30 \mathrm{~km}$ da capital do estado do Maranhão, no estremo leste da grande ilha de São Luís, próximo à baía de São José.

\begin{abstract}
A Associação foi formalizada por um grupo de artesãos em 04 de Abril de 2000. É uma entidade privada sem fins lucrativos que tem como finalidade trabalhar em benefício das pessoas carentes, pelo progresso da comunidade e pelo desenvolvimento das explorações artesanais em cerâmica, visando melhorar as condições de vida dos seus associados (LOPES, 2016).
\end{abstract}

As artesãs da associação trabalham de forma colaborativa, onde decisões são tomadas coletivamente. No entanto, há momentos para produção coletiva e momentos para produção individual, planejadas de acordo com sua organização interna. Segundo Lopes (2016), a presidente da associação afirma terem realizado cursos de capacitação em modelagem, em custos de produção, vendas, formulação de preços e os lucros, entre outros. Obtiveram o apoio do SEBRAEMA em várias fases durante aproximadamente dez anos.

A argila, principal matéria-prima, é oriunda de Rosário. Compram de oleiros, após limpeza de impurezas e armazenam em caixas de isopor. A produção na AASJR abrange a modelagem manual e sobre moldes de gesso, de esculturas e peças de decoração (Figura 01). Personagens da cultura local são representados nas peças produzidas, tais como a figura do pescador, pregoeiro, bumba meu boi, dançarinas de roda etc.

Figura 01: Produtos da AASJR

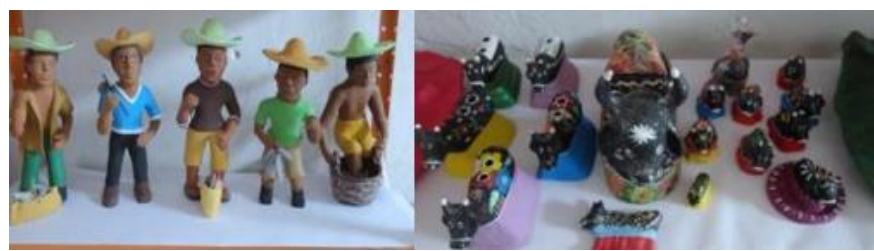

Fonte: Acervo do LDC, 2017.

\subsection{Olaria em Rosário}

A olaria do Sr. Amarildo localiza-se no município de Rosário na baixada maranhense. Sobre a origem da cidade Guará (2012, p. 23), diz que:

A cidade de Rosário está situada à margem esquerda do Rio Itapecuru, que foi uma das principais vias fluviais de acesso ao interior do Estado durante o período colonial. Uma área antes habitada por índios expulsos por imigrantes atraídos pelas riquezas das terras. A 
cidade teve origem com o povoado conhecido como Itapecuru Grande, onde havia uma igreja dedicada a Nossa Senhora do Rosário. O povoamento por colonizadores portugueses foi iniciado no século XVII, mas só em 1717 foi solicitado a criação da freguesia de Nossa Senhora do Rosário. Em 19 de abril de 1833 foi elevada à condição de Vila, e em 6 de abril de 1914 foi elevada à categoria de cidade pelo então governador do Estado do Maranhão, o Coronel Afonso Giafenig de Mattos (GUARÁ, 2012, p. 23).

Na localidade, polo de produção artesanal em cerâmica, encontra-se em abundância, tanto de matéria prima (argila) como produção de artefatos em cerâmica (GUARÁ, 2012). A cerâmica se concentra na indústria da construção civil, aplicada à produção de tijolos, telhas etc., no entanto, a produção artesanal é, também, um forte setor produtivo na região (Figura 02), caracterizando a quantidade de olarias presentes na cidade, antes cinquenta e nos dias de hoje aproximadamente quinze. As produções utilizam em essência a argila.

Figura 02: Produção de Peça em Argila (Técnica do Torno)

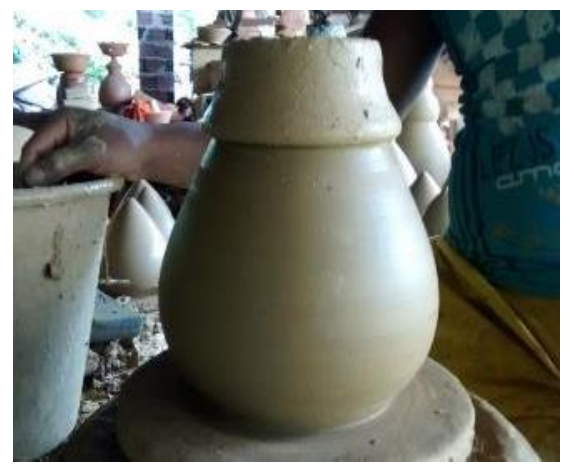

Fonte: Acervo do LDC, 2017.

As olarias são conhecidas pelos nomes dos proprietários. Na olaria do Senhor Amarildo, o uso do torno é tradicional e frequente, porém, nos últimos anos introduziram a modelagem sobre molde de gesso e as pinturas manuais, inclusive com a participação de mulheres na produção cotidiana. Os artefatos mais produzidos são: vasos, luminárias, filtros e objetos decorativos. A produção no torno e com os moldes de gesso é artesanal, e com peças semelhantes portadoras das características da manualidade relativa a cada artesão.

O processo de produção é rudimentar e consiste em etapas que se iniciam na retirada da argila no barreiro, passando pela limpeza, homogeneização, modelagem e demais etapas habituais no processo cerâmico artesanal. Guará (2012), diz que a argila presente em Rosário é empregada ao natural, sendo realizadas técnicas elementares, onde a argila, muitas das vezes, não passa por um processo adequado de beneficiamento, o que acarreta na diminuição da qualidade final dos artigos produzidos. Os processos são bem peculiares, onde os próprios artesãos, por vezes, desenvolvem seus próprios maquinários e ferramentas para a realização das atividades dentro da olaria.

\section{A Argila, Cerâmica e Pó de Osso (PO)}

O conhecimento fundamental sobre argila, cerâmica e pó de osso, se mostram importantes para embasar o trabalho desenvolvido e agregar valor frente às abordagens apresentadas para os grupos de produção artesanal. A exposição desses materiais e os processos que neles se inserem 
são aspectos pertinentes ao edificar as informações quanto ao saber dos métodos.

\subsection{A Argila}

A atividade ceramista permite a conformação de objetos a partir da matéria prima, argila. Norton (1973) fala que o alto grau de importância da argila é sem dúvida percebível, por ser o material central da cerâmica. Existem variações de argilas que podem ser aplicadas na produção em cerâmica artesanal e industrial.

Norton (1973, p. 26) fala ainda que "de um modo geral, as argilas são um produto secundário, na crosta terrestre, produzido pela alteração de rochas de tipo pegmatítico". Quanto à origem, podemos classificar as argilas em residuais que são encontradas na própria região das rochas que a originou e as argilas sedimentares que são formadas, sobretudo por regiões alagadas como pântanos e que transportam grande aditivo de matéria orgânica.

Frigola (2002), diz que as "argilas podem ser divididas em três tipos: vermelhas, brancas e refratárias". Ainda segundo a autora, as argilas vermelhas são formadas por vários elementos químicos, porém apresentam um elevado grau de óxido de ferro na sua composição, por isso proporcionam uma cor parda acinzentada. Após a queima essa cor varia entre vermelha e branca avermelhada, esse fenômeno ocorre de acordo com a temperatura que a peça é submetida no ato da queima. São argilas muito fundíveis e não devem ser cozidas a temperaturas acima de $1100{ }^{\circ} \mathrm{C}$, tornando-se mais escura à medida que se aproxima desta temperatura máxima.

\subsection{A Cerâmica}

Segundo a Associação Nacional dos Fabricantes de Cerâmica - ANFACER (2016), a cerâmica é o material artificial mais antigo produzido pelo homem. A origem da cerâmica brasileira:

\section{[...] tem seus primórdios na llha de Marajó. A cerâmica marajoara aponta à avançada cultura indígena que floresceu na ilha. Estudos arqueológicos, contudo, indicam a presença de uma cerâmica mais simples, que indica ter sido criada na região amazônica por volta de cinco mil anos atrás (ANFACER, 2016).}

$\mathrm{Na}$ atualidade, a cerâmica é empreendida em múltiplos processos produtivos no setor das grandes indústrias que trabalham com esse domínio. Construção civil, indústrias de revestimentos cerâmicos e decoração, dentre outras esferas industriais praticam suas atividades utilizando esse elemento como um dos principais. No entanto, a produção cerâmica artesanal ainda é um forte setor e que ainda não submergiu aos atualizados processos de produção, pelo contrário, só evoluciona de forma a agregar importância ao modo como hoje o trabalho é realizado.

No Brasil existem grandes polos ceramistas e o estado do Maranhão tem algumas localidades voltadas a esse fazer. É conhecido que existem variados tipos de argila, cada uma com sua especificidade e logo a argila presente em Rosário-Maranhão é a do tipo vermelha, que apresenta forte presença do óxido de ferro na sua composição.

\subsection{O Pó de Osso}

Guimarães (2015) fala que se deve ter a preocupação no tocante ao aproveitamento dos resíduos sólidos e sua produtividade, elaborando uma direção para a própria cadeia produtiva ou para cadeias produtivas diferentes.

Os resíduos sólidos, no entanto, possuem suas classificações, que define suas categorias e logo sua correlação com o descarte adequado. Concentrando a atenção para a NBR 10004 (ABNT, 
2004) no item 4.1, quanto à classificação dos resíduos sólidos, existe: resíduos da classe I - Perigosos; classe II - Não perigosos; -classe II A - Não inertes. - e resíduos da classe II B - Inertes. Os da Classe I (Perigosos) são, segundo a norma, os que apresentam algum tipo de periculosidade como: Inflamabilidade, Corrosividade, Reatividade, Toxicidade e Patogenicidade. A Classe II (Não Perigosos) refere-se aos resíduos que não transmitem risco de periculosidade, como exemplos: restos alimentícios de restaurantes, resíduos de borracha e madeira, areia de fundição, bagaço de cana de açúcar etc. Os rejeitos classificados na Classe II A (Não Inertes) correspondem aqueles que poderão possuir propriedades especificas como a biodegradabilidade, combustibilidade ou solubilidade em água. Por fim, os resíduos da Classe II B (Inertes) são:

Quaisquer resíduos que, quando amostrados de uma forma representativa, segundo a ABNT NBR 10007, e submetidos a um contato dinâmico e estático com água destilada ou desionizada, à temperatura ambiente, conforme ABNT NBR 10006, não tiverem nenhum de seus constituintes solubilizados a concentrações superiores aos padrões de potabilidade de água, excetuando-se aspecto, cor, turbidez, dureza e sabor (ABNT, 2004).

Pautado nessa classificação pode-se afirmar que o objeto de estudo deste trabalho se qualifica na Classe II, pois o Pó de Osso é um material não perigoso e se enquadra nos resíduos provenientes de restaurantes, como citado em exemplo pela NBR 10004 (ABNT, 2004).

Várias discussões são feitas sobre o aproveitamento dos resíduos, gerados pelo consumo. É de suma importância agregar esse fator na sociedade em que vivemos, onde o consumo aumenta cada vez mais e a geração de dejetos acresce em proporção. Ribeiro (2014) argumenta que na corrida pela diminuição do abuso gerado pelo descarte irregular de dejetos no ambiente, pode-se observar uma escolha positiva, aumentar a vida útil dos objetos, não amortecendo os possíveis impactos ainda causados, contudo, diminuindo a constância com que incidem, e logo, dos impactos gerados.

O pensamento que consiste em aumentar a vida útil dos produtos, ainda que pequeno em potencial, para resolver o problema do descarte de resíduos no ambiente, pode ser uma possível solução preliminar. No entanto, o reaproveitamento de recursos oriundos desse descarte pode ser atrelado a outros materiais e então constituírem outros objetos. No Brasil, o pó de osso é um material que se adéqua a essa possibilidade, pois o território brasileiro é rico e desenvolvido na indústria pecuária e permite, então, o reuso desse componente, contribuindo para uma melhor destinação final desse rejeito sólido.

Vivemos em um país onde a pecuária é abundante, a ação de aproveitamento do osso bovino se torna facilitada. Guimarães (2015, p. 36) afirma que, "[...] devido ao grande rebanho, os ossos correspondem a uma matéria-prima acessível, de grande disponibilidade no Brasil, encontrados em matadouros, açougues, supermercados e demais estabelecimentos alimentícios". Outros usos, como na adubagem de plantas e na dieta nutricional de outros animais o pó de osso é empregado, fazendo juiz ao seu papel colaborador no reaproveitamento de seu recurso.

O osso bovino é um material renovável, visto que após o beneficiamento dos produtos oriundos da pecuária os ossos sobejam descartados na natureza, onde então, promove-se o resgate desse material para possível emprego em outros setores de produção. O fato dessa atividade ser considerada renovável, se dar pela caracterização da saída de um ambiente, que antes era considerado lixo, descarte e passa a se tornar membro essencial para a produção de outros produtos derivados de osso bovinos. 


\section{O Compósito}

O conceito de compósito segundo Félix (2013) consiste no resultado de uma combinação entre dois ou mais elementos ou materiais diferentes em relação às suas propriedades físicas. Sendo que, o objetivo dessa composição heterogênea consiste na geração de características dos componentes na possibilidade de apresentarem um melhor desempenho no tocante à estrutura em determinadas condições de uso. Logo, podemos denominar a união do pó de osso e argila como sendo um compósito, para tanto, faz-se necessário compreender as etapas nas quais o osso é associado ao material argiloso e, por conseguinte, à produção de peças cerâmicas. As experimentações utilizam ossos bovinos na produção de peças em cerâmica, logo, importa apresentar o processo-beneficiamento desse substrato.

Os ossos bovinos são facialmente encontrados em estabelecimentos alimentícios, logo esses ossos adquiridos são lavados com o desígnio de remover possíveis impurezas que ainda podem se encontrar aderidas às paredes dos ossos. A secagem configura o segundo processo, nessa fase a própria insolação é capaz de fazer com que a água presente nos ossos evapore. Em seguida levamse os ossos a um forno, em uma temperatura preestabelecida de $1000{ }^{\circ} \mathrm{C}$ para realizar a calcinação do material.

Após a queima, os ossos passam pela trituração, esse processo consiste em fragmentar o osso em diminutos pedaços. Podem ser empregadas máquinas trituradoras elétricas, bem como, pilões manuais. Essa trituração é importante na fase de peneiramento, configurando-se na última etapa do processo. As peneiras utilizadas para a conquista do pó de osso foram as de número e identificação 30 e 60 mesh. Logo se obtêm o pó de osso bovino processado e pronto para ser vinculado à massa argilosa e configurar peças em cerâmica.

Logo, no tocante a elaboração do compósito, essa etapa se configura como sendo a primeira. Essa atividade resulta em um pó de osso com diferentes níveis de granulometria. No caso do compósito estudado nesta pesquisa, a peneira 60 mesh foi a escolhida para compor os produtos cerâmicos e a peneira 30 mesh foi também utilizada no processo de preparação das pastilhas para alguns testes na etapa da vitrificação.

Na segunda etapa desse processo é realizada a mistura/homogeneização da argila com o pó de osso para a produção das peças. As quantidades de osso e argila empregados nas amostras e nos artefatos foram determinadas por uma proporção definida de $30 \%$ de pó de osso e $70 \%$ de argila, seguindo a recomendação das pesquisas anteriormente realizadas pelo LDC. Sendo assim o uso do pó de osso nos produtos em cerâmica reduz em até 30\% a retirada da argila no barreiro, o que minimiza os impactos gerados ao ambiente.

\subsection{Preparando o Compósito}

Comungando conhecimento junto aos agentes envolvidos na pesquisa e abordando apreciações acerca dos conhecimentos desenvolvidos pelo grupo do LDC, sabe-se que a obtenção do compósito deve seguir algumas etapas que normatizam o processo, tais como: (a) verificação do peso da quantidade de argila (seca ou úmida) que se pretende utilizar; (b) de acordo com o peso, desenvolver cálculo da quantidade de pó de osso que irá precisar; (c) após a preparação da argila (conforme já visto acima), ocorre à mistura do pó de osso com a argila úmida. Procedida à homogeneização, faz-se necessário o amassamento da argila na tentativa de remover prováveis bolhas de ar e para torná-la consistente e plástica; 


\section{Vitrificação}

As peças cerâmicas possuem um processo de acabamento que consiste na cobertura vítrea (vidro) de sua superfície. A vitrificação ou esmaltação configura esse processo. Muitas são as vantagens da vitrificação, pois esse tipo de acabamento promove a resistência a arranhões, além de proporcionar efeitos estético-visuais diversos. A transparência e o aspecto incolor são características do vidrado ou esmaltado no seu aspecto natural. Só ocorrem modificações de cor quando esses elementos são atrelados pelo adicionamento de vidrados base, transparente e incolor, óxidos ou colorante (LACAD, 2016).

Logo, os vidrados podem assumir aspectos transparentes, translúcidos, opacos, brilhantes, acetinados, foscos, incolores ou coloridos, com ou sem a presença do elemento chumbo (Pb). Os vidrados de fritas se configuram em pós, que ao misturado em água, transformam-se em um líquido viscoso pronto para ser aplicado sobre a peça.

Caracas (2016) fala que "[...] vitrificar objetos em cerâmica é tarefa delicada que implicará em estudo e prática cotidiana para que o conhecimento das particularidades do processo seja construído". Apresentamos também esses conhecimentos aos grupamentos artesanais, demonstrando as diferentes técnicas que foram utilizadas no processo para a realização das pinturas em cerâmica através da vitrificação, podendo ser por banho, imersão, pincel.

A esmaltação por banho (derramando o vidrado sobre a peça) consiste no banho literal da peça em cerâmica, onde o material é preparado (esmalte e água) e despejado sobre a peça. Em geral, para uma boa cobertura do esmalte é necessário realizar dois ou três banhos, o que depende da viscosidade do vidrado.

Esmaltação por imersão (mergulhando a peça no vidrado) é um processo simples, mas que possui suas peculiaridades. A terminologia da técnica já explica como ela é empregada, a peça é imersa no vidrado, podendo ser de forma parcial ou integral. A utilização de uma quantidade maior de esmalte se faz necessário para essa técnica, haja vista, que em quantidades pequenas o mergulho deve ser efetivado por partes.

Já a esmaltação com pincel consiste na pintura de peças com pincel. Para retoques ou pintura com detalhes (desenhos, grafismos etc.), o pincel, preferencialmente, macio e com cerdas arredondadas, é utilizado sem que as cerdas do pincel toquem a superfície da peça, ou seja, a pintura é realizada "rolando" a gota do vidrado. Utiliza-se a ponta do pincel e a gota do vidrado é depositada sobre a superfície do artefato.

\section{Experiências em Produtos}

Procedimentos de modelagens conquistaram cada vez mais espaço nos saberes tradicionais e nos setores indústrias. As técnicas de produção em cerâmica, com o passar dos tempos, foi sendo cada vez mais aprimorada. Esse fator desenvolvedor fez surgir áreas de conhecimento cada vez mais expandidas, pois a cerâmica consente uma gama de possibilidades em virtude da sua utilização e aplicação em diversos setores, onde se circunda inclusive, a produção artesanal e industrial.

Compreender detalhadamente os processos da modelagem se torna necessário, entretanto, tendo em vista que as técnicas possuem etapas específicas essencialmente conhecidas e repetidas por ceramistas. A escolha, aqui, é apontar algumas observações empíricas a partir das experiências realizadas com o uso do compósito e também explorar as técnicas que já são praticadas nos grupos 
artesanais.

\subsection{Modelagem Manual}

Esta modelagem faz uso principalmente da palma das mãos, dos dedos e alguns instrumentos específicos que auxiliam na fase de detalhamento dos desenhos e entalhes. Quando a modelagem manual foi realizada com o compósito, observou-se que: a) a massa cerâmica decorrente da argila com pó de osso se torna menos plástica e seca mais rapidamente; b) devido à diminuição da plasticidade, inicialmente, ocorre um estranhamento na manipulação da massa argila com PO. No entanto, é apenas inicial e a modelagem é totalmente viável; c) para a realização do processo de esvaziamento ou ocagem, recomenda-se o uso de um fio, que costuma ser do tipo nylon, para a realização de cortes seccionais e angulares na peça; d) em geral, as peças com o compósito pouco deformam ou criam rachaduras.

\subsection{Modelagem com Placas}

Trata-se de uma modelagem a ser feita de duas formas. A primeira delas é a abertura de placa, utilizando rolo manual e peças de madeira de igual espessura para nivelar e definir a espessura da placa. A segunda é a utilização de uma plaqueira, equipamento que consiste numa mesa com dois cilindros manuseados e regulados através de uma manivela. Com esse equipamento, o esforço físico é reduzido e tem-se um maior controle da espessura da placa. Nos dois casos, o compósito previamente preparado é colocado entre tecidos (Iona), prensado pelos rolos. $\mathrm{O}$ uso do compósito apresenta as mesmas características citadas na modelagem manual.

\subsection{Modelagem em Torno}

Para o torneamento, a argila com pó de osso gera o estranhamento citado nas outras modelagens, logo deve estar levemente mais úmida que a argila comum. Observou-se que o compósito, no torneamento, apresenta as condições semelhantes ao uso da argila sem PO, ou seja, conforme Caracas et. al. (2016), para tornear peças é indispensável à utilização de um bloco ou bola de argila e que esse material não apresente bolhas de ar ou impurezas. A argila precisa proporcionar um aspecto uniforme no intento de suportar o manuseio do trabalho e a água que for acrescida na realização do trabalho no torno.

\subsection{Modelagem sobre Forma}

A modelagem de artefatos em cerâmica sobre formas requer a confecção de moldes. No LDC, utilizam-se formas de gesso, considerado um material acessível e, também, porque as artesãs de São Jose de Ribamar e os oleiros de Rosário já utilizam esta técnica. Na modelagem sobre formas são prensadas as massas ou placas retiradas da plaqueira. As formas de gesso promovem a qualidade dos detalhes. Quando o compósito é utilizado como placa prensada ou pressionada sobre a forma, os resultados são positivos. Os detalhes são preservados e o manuseio é semelhante ao da argila sem pó de osso, sendo que os cuidados citados na modelagem manual quanto à plasticidade, secagem, rachaduras etc., permanecem.

\section{Design de Superfície e Melhores Resultados}

Rüthschilling (2008) afirma que as civilizações da pré-história já apreciavam o ato de decorar superfícies, essencialmente, os de uso doméstico, arquitetônico e têxtil. Logo, dois setores se desenvolveram, sendo a cerâmica e a tecelagem, não necessariamente nesta ordem. Com o advento dos conhecimentos a azulejaria surgiu, carregando o DNA do que hoje é chamado de design de 
superfície.

“À medida que novos materiais, tecnologias, suportes e aplicações estão surgindo, a ampliação do conceito de Design de Superfície tem sido objeto de discussão em diversos níveis de atuação [...]" (RÜTHSCHILLING, 2008). O design de superfície é uma área em expansão no Brasil, onde podemos observar sua aplicabilidade em diversas especialidades. Seus elementos, como a forma, textura, cor e seus materiais abrangem aspectos que perpassam dos naturais e rústicos aos industriais e refinados, indo além da função prático-funcional e explorando a função estéticosimbólica.

No LDC, realizaram-se experiências relativas ao design de superfície tanto em produtos, quanto em pastilhas ou amostras. Produtos foram feitos mantendo o acabamento natural do compósito, que gera uma cor mais clara devido aos pontos brancos do pó de osso. Fez-se também, testes aplicando esmaltes, ou seja, vitrificando tanto peças com o compósito quanto sem o compósito.

A inserção do pó de osso bovino traz consigo propriedades favoráveis ao design de superfície, capazes de fornecer bases para a inovação no processo de vitrificação. Alguns esmaltes, especificamente, originaram na superfície das peças, um efeito rústico, distinto da cerâmica artesanal existente na região. Outros esmaltes apresentaram o mesmo resultado tanto nas peças em argila com pó de osso, quanto sem pó de osso. Em algumas situações o esmalte sobre o compósito só apresentou diferenças ou maior rusticidade quando a vitrificação foi realizada a 1150 ${ }^{\circ} \mathrm{C}$.

É importante destacar, que a vitrificação em cerâmica, sem o compósito, já agrega valor, pois o vidrado promove uma qualidade estética polida ou brilhosa e colorida. Tradicionalmente, no setor cerâmico o acabamento vítreo gera distinções quanto ao valor estético, econômico e cultural, relacionados aos resultados associados à temperatura de queima. Em geral, observa-se no mercado, especialmente o artesanal, que peças com design de superfície decorrente de queimas acima de $1150{ }^{\circ} \mathrm{C}$ tem maior valor agregado, com resultados mais inusitados, únicos.

Os produtos foram projetados pela equipe do LDC e executados em parceria com os grupamentos artesanais, mostrando possibilidades, além de promover a interação e experimentação do uso do compósito e alguns projetos contaram com alunos voluntários. São artefatos projetados, visando usos multifuncionais, ou seja, o mesmo projeto de produto, com pequenas alterações pode possuir funções distintas como vaso, luminárias para ambientes externos ou internos, objetos de jardim ou interiores etc. São utilizados individualmente ou em conjunto, onde nomes indígenas -Tupy Guarani - representaram o conceito estético formal da maioria dos produtos. 
Figura 03: Resultados em Produtos
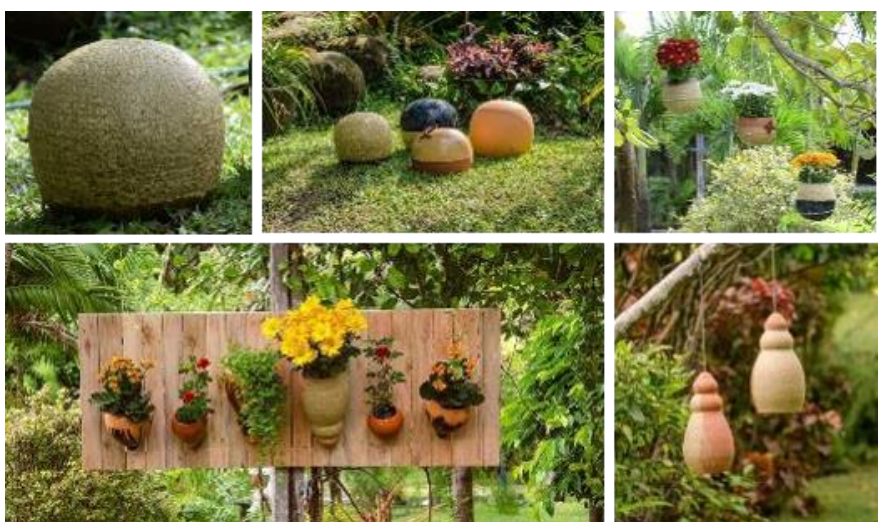

Fonte: Acervo LDC, 2017

Figura 04: Resultados em Produtos
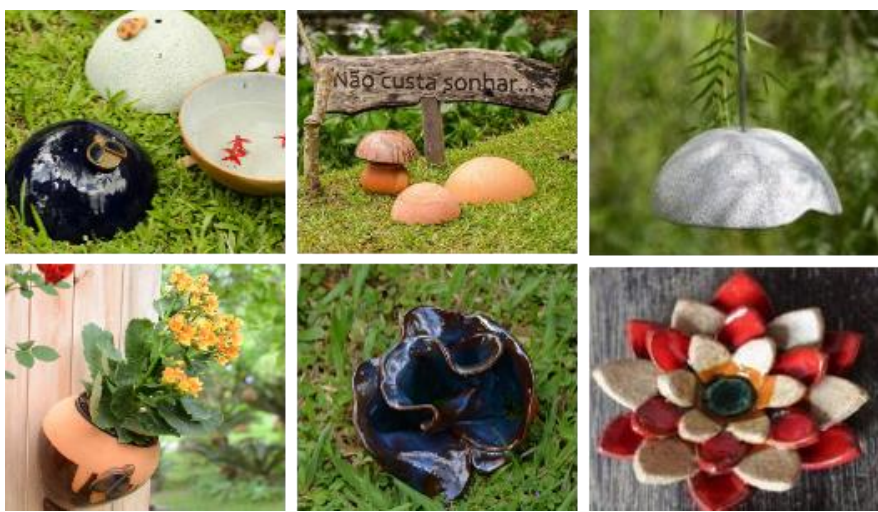

Fonte: Acervo LDC, 2017

\section{Conclusão}

A produção artesanal se destaca por ser um setor de grande importância para inúmeros indivíduos, espalhados pelos territórios. Muitos incentivos devem ser fomentados no tentame da preservação das atividades proeminentes dessa cultura. Cabe também ao design, o papel de agente facilitador no tocante a interação e integração dos conhecimentos acerca desses dois campos, geradores de experiências. Este trabalho empregou sua atenção a esse fator, onde pesquisadores designers procuraram primeiramente o entendimento do fazer artesanal, buscando sempre respeitar e contribuir para sua ampliação

No artesanato, a cerâmica é outro ponto chave, onde se buscou valorar os trabalhos realizados nos grupos artesanais maranhenses estudados, tributando no enriquecimento e preservação dessa atividade. É sabido que a falta de apoio e a não perpetuação da cultura artesanal acaba por incentivar o sentimento de decadência desse setor. Entretanto, a pesquisa apresentada visou à exposição de novas tecnologias disponíveis, na tentativa de contribuir para uma mudança de cenário, fazendo com que a valorização aos produtos e produtores volte a ser um fator emergente. 
A pesquisa e as peças projetadas trouxeram aspectos relevantes gerando novas possibilidades ao design de produto e superfície. Os resultados da pesquisa foram favoráveis, desaguando em novos usos, novas texturas, cores e tons através do uso do compósito e das técnicas de vitrificação.

Conclui-se que as fases de preparação da argila são recorrentes e/ou semelhantes no fazer artesanal. A inserção do pó de osso significa introduzir uma nova etapa nessa preparação. Trata-se de uma etapa em que o material é acessível e não acrescenta maiores custos. Implica sim um pouco mais de investimento em tempo que é considerado compensatório devido às vantagens observadas e adquiridas.

Durante a fase observação detectou-se que as peças sem o compósito tendem a danificar com mais frequência devido às possíveis irregularidades nos processos de modelagem, devido à retração pela perda de água, e quando acontece à deformidade ou quebra com a queima, a solução é muito restrita ou não é possível, gerando perda de material e tempo. O compósito, em geral, favorece a diminuição de possíveis rachaduras na secagem e cozedura. Algumas peças, mesmo quando trincadas na modelagem, não apresentam posterior evolução da área de trinca. O osso, já calcinado, não sofre mais perda de água na sua composição, durante a queima da cerâmica. Logo, isso ajuda para um menor índice de retração, favorecendo, inclusive um melhor controle das dimensões das peças.

A vitrificação sobre peças com a inserção do pó de osso configurou-se num fator de inovação e diferenciação aos produtos $\mathrm{O}$ aspecto visual da cerâmica com o compósito, distingue-se pela sua rusticidade e singularidade capaz de promover a valorização dos produtos juntos aos grupos produtores artesanais.

O apoio da Fundação de Amparo à Pesquisa e ao Desenvolvimento Científico e Tecnológico do Maranhão - FAPEMA, do Conselho Nacional de Desenvolvimento Científico e Tecnológico - CNPQ e dos Programas Institucionais de Bolsas de Iniciação em Desenvolvimento Tecnológico e Inovação - PIBITI e de Iniciação Científica - PIBIC, se destacam como elementos fundamentais para a evolução do aprendizado e, por conseguinte, para a valorização da produção científica.

\section{Referências}

ANFACER. História da Cerâmica. Disponível em: <http://www.anfacer.org.br/historia-ceramica>. Acesso em: 11 nov. 2016.

ASSOCIAÇÃO BRASILEIRA DE NORMAS E TÉCNICAS. NBR 10004: Resíduos sólidos - Classificação. 2 ed. Rio de Janeiro: Abnt, 2004. 71 p.

CARACAS, Luciana et al (Org.). Mestiço: design e produto cerâmico no maranhão. São Luís: Ufma, 2016. 74 p. Manual Catálogo.

FÉLIX, Vinícius Carvalho Pacheco. Materiais Compósitos. 2013. Disponível em:<http://www.ebah.com.br/content/ABAAAgOwUAC/materiais-compositos>. Acesso em: 26 nov. 2016.

FRIGOLA, Dolors R. I. Cerâmica. Lisboa, Editorial Estampa, 2002.

GUARÁ, Thiago Duarte; Design e produção artesanal em cerâmica: um estudo de caso em Rosário - MA, 2012. 
GUIMARÃES, Karoline de Lourdes Monteiro. ANÁLISE DA ADIÇÃO DE RESÍDUOS DE OSSOS BOVINOS E ROCHAS ORNAMENTAIS EM MASSA CERÂMICA BRANCA PARA A UTILIZAÇÃO EM PROCESSOS DE CONFORMAÇÃO. 2015. 125 f. Dissertação (Mestrado) - Curso de Design, Universidade Federal do Maranhão, São Luis, 2015.

KRUCKEN, Lia. Valorização de identidades e produtos locais. São Paulo, Studio Nobel, 2009

LACAD - Laboratório de Cerâmica Artística à Distância. Disponível em:<http:// www.ufrgs.br/lacad/revestvidrado.html>. Acesso em: 21 jun. 2016.

LOPES, Sandro. SOBRE A ASSOCIAÇÃO DOS ARTESÃOS DE SÃO JOSÉ DE RIBAMAR. Disponível em: <http://aasjribamar.blogspot.com.br>. Acesso em: 10 nov. 2016.

MANZINI, Ezio. Design para a inovação social e sustentabilidade: comunidades criativas, organizações colaborativas e novas redes projetuais. Rio de Janeiro: E-papers, 2008.104p.

MANZINI, Ezio; VEZZOLI, Carlo. O Desenvolvimento de Produtos Sustentáveis: Os requisitos ambientais dos produtos industriais. 1ạ Edição. São Paulo: Editora da Universidade de São Paulo, 2005.

MARTINS, L.R. RELATOS DE MÃOS: a produção artesanal da cerâmica em Rosário-MA, 2013, 100 f. (Mestrado em Desenvolvimento Socioespacial e Regional) -Universidade Estadual do Maranhão, São Luis, 2013.

NORTON, F. H. Introdução à tecnologia cerâmica, tradução de Jefferson Vieira de Souza. São Paulo: Edgard Blucher, p. 324, 1973.

RIBEIRO, Samyra dos Santos et al. Revestimento de parede com placas de circuito impresso de computadores e cerâmica: design e inovação. In: CONGRESSO BRASILEIRO DE PESQUISA E DESENVOLVIMENTO EM DESIGN, 11., 2014, Gramado. Anais... . Gramado: Ufma, 2014. p. 2 - 12.

RÜTHSCHILLING, Eveliseb Anicet. Design de Superfície. Porto Alegre: Ufrgs, 2008. 104 p.

THACKARA, John. Plano B: O design e as alternativas viáveis em um mundo complexo. São Paulo: Saraiva, 2008. 304 p. 